Check for updates

Cite this: Phys. Chem. Chem. Phys. 2021, 23, 16564

Received 18th June 2021 Accepted 19th July 2021

DOI: $10.1039 / \mathrm{d} 1 \mathrm{cp} 02758 \mathrm{a}$

rsc.li/pccp

\section{A structure activity relationship for ring closure reactions in unsaturated alkylperoxy radicals $\dagger$}

\author{
L. Vereecken, (D)*a $G$. Vu, ${ }^{b}$ A. Wahner, (D) ${ }^{a}$ A. Kiendler-Scharr $\left(\mathbb{D}^{a}\right.$ and \\ H. M. T. Nguyen (D)*b
}

Terpenoids are an important class of multi-unsaturated volatile organic compounds emitted to the atmosphere. During their oxidation in the troposphere, unsaturated peroxy radicals are formed, which may undergo ring closure reactions by an addition of the radical oxygen atom on either of the carbons in the $\mathrm{C}=\mathrm{C}$ double bond. This study describes a quantum chemical and theoretical kinetic study of the rate of ring closure, finding that the reactions are comparatively fast with rates often exceeding $1 \mathrm{~s}^{-1}$ at room temperature, making these reactions competitive in low-NOx environments and allowing for continued autoxidation by ring closure. A structure-activity relationship (SAR) is presented for 5- to 8-membered ring closure in unsaturated $\mathrm{RO}_{2}$ radicals with aliphatic substituents, with some analysis of the impact of oxygenated substituents. $\mathrm{H}$-migration in the cycloperoxide peroxy radicals formed after the ring closure was found to be comparatively slow for unsubstituted $\mathrm{RO}_{2}$ radicals. In the related cycloperoxide alkoxy radicals, migration of $\mathrm{H}$-atoms implanted on the ring was similarly found to be slower than for non-cyclic alkoxy radicals and is typically not competitive against decomposition reactions that lead to cycloperoxide ring breaking. Ring closure reactions may constitute an important reaction channel in the atmospheric oxidation of terpenoids and could promote continued autoxidation, though the impact is likely to be strongly dependent on the specific molecular backbone.

\section{Introduction}

The chemistry of peroxy radicals $\left(\mathrm{RO}_{2}\right)$ has received increased interest over the last decade. In combustion systems, the $\mathrm{H}$-migration in peroxy radicals has been shown to be a source of $\mathrm{OH}$ radicals in low-temperature combustion. ${ }^{1-3}$ Similar $\mathrm{H}$-migration processes have been shown to be important in the atmosphere in regenerating $\mathrm{OH}$ radicals, ${ }^{4}$ the most important radical oxidizing volatile organic compounds (VOCs). H-Migration in $\mathrm{RO}_{2}$, followed by $\mathrm{O}_{2}$ addition on a product alkyl radical, is also the critical reaction sequence in the so-called autoxidation of VOCs, where successive $\mathrm{H}$-migration $/ \mathrm{O}_{2}$-addition events can lead to highly oxidized molecules (HOMs)..$^{5-9}$ Such molecules typically have a low vapor pressure, and can readily transition to the aerosol phase, affecting air quality and climate change. The rate of $\mathrm{H}$-shift

\footnotetext{
${ }^{a}$ Institute for Energy and Climate Research: IEK-8: Troposphere, Forschungszentrum Jülich GmbH, Jülich, Germany. E-mail: L.Vereecken@fz-juelich.de

${ }^{b}$ Faculty of Chemistry and Center for Computational Science, Hanoi National University of Education, Hanoi, Vietnam.E-mail: Hue.Nguyen@hnue.edu.vn $\dagger$ Electronic supplementary information (ESI) available: Details on the algorithm for the conformer search; the geometries, rovibrational characteristics and energies of all reactants, TS and products characterized in this study are available at the M06-2X level of theory. Where available, $\operatorname{CCSD}(\mathrm{T})$ energies and $\mathrm{T} 1$ diagnostics are also provided. See DOI: 10.1039/d1cp02758a
}

reactions depends strongly on the distance migrated, as well as on substituents in the molecule; ${ }^{10-14}$ particularly favorable are $\mathrm{H}$-atoms from oxygenated groups (aldehydes, alcohols) and $\beta$-unsaturated moieties leading to allyl-resonance stabilized product radicals. ${ }^{11}$

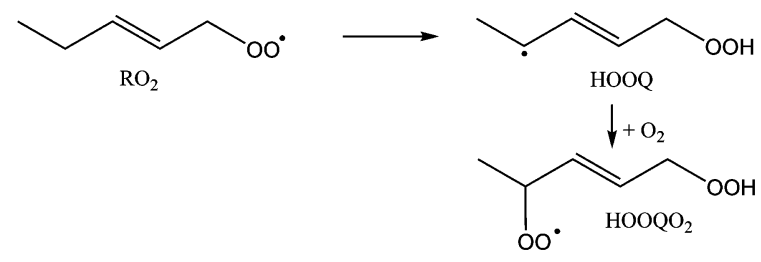

Due to the much stronger $=\mathrm{C}-\mathrm{H}$ bond on carbons with a double bond, vinylic $\mathrm{H}$-atoms do not migrate at a rate competitive to other atmospheric processes, and in autoxidation processes, the double-bonded carbons are thus more difficult to activate and oxidize, limiting the oxygen to carbon ratio O:C. In the atmosphere, however, the highest emissions of non-methane VOCs consist of isoprene $\left(\mathrm{C}_{5} \mathrm{H}_{8}\right)$, monoterpenes $\left(\mathrm{C}_{10} \mathrm{H}_{16}\right)$, and other terpenoids, ${ }^{15}$ most of which are (poly-)unsaturated compounds. Even for these compounds, highly oxidized compounds were measured with very high $\mathrm{O}: \mathrm{C}$ ratios, ${ }^{7,9,16-19}$ indicating that all carbons can be oxidized without breaking the molecular backbone. 
One of the pathways that enables the oxidation of double-bonded carbons in a molecule is a ring closure reaction:

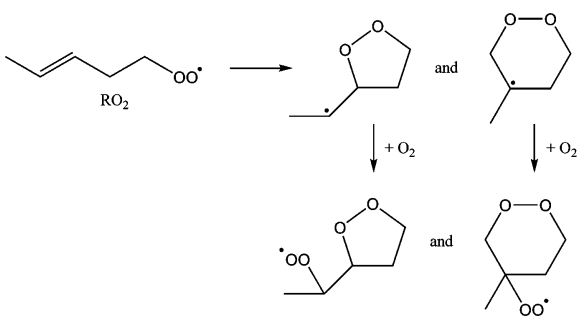

Ring closure reactions in $\mathrm{RO}_{2}$ and alkoxy radicals have been studied theoretically, ${ }^{20-27}$ and mechanisms incorporating these reactions for some compounds ${ }^{28}$ have been shown to provide a better agreement with experimental data. Still, these studies focused on a subset of molecules, and no structure-activity relationship (SAR) is available to enable systematic inclusion of such ring closure reactions in atmospheric chemical mechanisms.

In this work, we describe a theory-based SAR for ring closure in unsaturated $\mathrm{RO}_{2}$ radicals, examining 4- to 8-membered ring formation in linear and branched olefines. This SAR is directly applicable in mechanism development, can be readily implemented in software-assisted mechanism generation software such as GeckoA $^{29,30}$ or SAPRC, ${ }^{31}$ and serves as a guide for further extensions examining a wider range of substituents. We also examine the ability of the product cycloperoxide radicals to undergo further autoxidation steps by $\mathrm{H}$-migration, either at the peroxy radical or alkoxy radical stages of their subsequent chemistry.

\section{Methodology}

The geometries and rovibrational characteristics of all conformers of the reactants and transition states were first optimized at the M06-2X/cc-pVDZ level of theory, ${ }^{32,33}$ performing an exhaustive search of the conformational space of all internal rotors and ring structures (see ESI $\dagger$ for more details). The ring closure alkyl radical products were likewise characterized, though here the conformational space was not comprehensively covered in all cases as the alkyl radical products don't contribute to the reaction kinetics. All structures obtained thus were then re-optimized at the M06-2X/aug-cc-pVTZ (ring closure) or M06-2X-D3/aug-ccpVTZ (H-migration) level of theory, ${ }^{32-34}$ with a harmonic frequency analysis performed at the same level of theory. ZPE corrections and partition function calculations are based on this data, using a wavenumber scaling factor of $0.971 .^{35,36}$ Finally, the relative energy of the transition state and products was further improved by single point calculations at the $\operatorname{CCSD}(\mathrm{T})$ /aug-cc-pVTZ level of theory ${ }^{37}$ on the lowest-energy conformers of reactant and TS. For molecules with multiple low-lying conformers, several of the lowest-lying conformers were examined at this level of theory to ensure the lowest energy structure at the coupled cluster level was used in calculating the barrier heights. T1 diagnostics (see ESI $\dagger$ ) indicate that no strong multi-reference character is expected for any of the structures. $^{38,39}$
The rovibrational data at the M06-2X or M06-2X-D3/aug-ccpVTZ level combined with ZPE-corrected $\operatorname{CCSD}(\mathrm{T})$ barrier heights were then used to predict the thermal rate coefficient in a rigid rotor harmonic oscillator multi-conformer transition state theory (MC-TST) approximation, ${ }^{40}$ incorporating all conformers. Tunneling corrections are included based on an asymmetric Eckart barrier paradigm. ${ }^{41,42}$ As the reaction rates are low compared to the thermalization rate by collisions with the bath gas, no pressure dependence is expected under atmospheric conditions. As discussed below, the reverse reactions are expected to be too slow to compete, and no rate corrections were implemented for reverse reactions.

\section{Ring closure reactivity trends}

The barrier heights and rate coefficients for all the ring closure reactions are provided in Table 1 . We have also collected calculations and literature data on ring closure in oxygenated $\mathrm{RO}_{2}$ radicals in Table 2 .

\subsection{Ring size and site of attack on the double bond}

The size of the ring structure is a key parameter in the rate of reaction, where especially smaller rings suffer from an energetic disadvantage due to ring strain. The ring strain is furthermore influenced by whether the ring closure occurs on the nearer or farther carbon of the double bond. Formation of 4-membered rings is energetically unfavorable, being endothermic by $\sim 20 \mathrm{kcal} \mathrm{mol}^{-1}$ and requiring surmounting a high energy barrier of around $30 \mathrm{kcal} \mathrm{mol}^{-1}$. All other ring closure reactions are roughly thermoneutral, within a few kcal $\mathrm{mol}^{-1}$. 5-Membered ring closure in $\beta$-unsaturated $\mathrm{RO}_{2}$ radicals, however, still has a high energy barrier exceeding $30 \mathrm{kcal} \mathrm{mol}^{-1}$ owing to the geometric disadvantage of having the double bond inside the tight TS ring structure. In contrast, $\gamma$ - and $\delta$-unsaturated $\mathrm{RO}_{2}$ radicals, forming 5-/6- and 6-/7-membered rings respectively, have energy barriers to ring closure that are only half as high, and where the ring closure on the nearer unsaturated carbon is typically more favorable as it does not have the rigid olefinic moiety in the TS cycle. For even wider separations between the peroxy radical site and the double bond, i.e. $\varepsilon$-unsaturated $\mathrm{RO}_{2}$ and beyond, the larger ring can accommodate the double bond more easily without undue ring strain, and ring closure on the outer carbon becomes more favorable.

\subsection{Substituents on the double bond}

Alkyl substitution impacts ring closure by affecting the electron density in the attacked double bond, by stabilizing the product alkyl radical, and through steric hindrance in the cyclisation process. Generally, a more substituted double bond, and a more substituted product radical site yields higher rate coefficients, where a fully substituted double bond has a rate coefficient for ring closure 3 to 4 orders of magnitude faster at $298 \mathrm{~K}$ than an unsubstituted terminal olefine. Furthermore, the stereospecificity of the substitution is important, as cis- and transsubstituted double bonds can have rate coefficients differing by 
Table 1 Site- and stereo-specific ring closure reactions in unsaturated aliphatic $\mathrm{RO}_{2}$ radicals. Indicated are the barrier height $E_{\mathrm{b}}\left(\mathrm{kcal}\right.$ mol $\left.{ }^{-1}\right)$ and relative energy of the ring product $E_{\text {ring }}\left(\mathrm{kcal} \mathrm{mol}^{-1}\right)$ at the $\operatorname{CCSD}(\mathrm{T}) / / \mathrm{MO} 06-2 \mathrm{X} / \mathrm{aug}-\mathrm{cc}-\mathrm{pVTZ}$ level of theory, as well as the rate coefficient at $298 \mathrm{~K}$ and as a Kooij expression $k(200-450 \mathrm{~K})=A \times(T / K)^{n} \times \exp \left(-E_{\mathrm{a}} / T\right)\left(K(298 \mathrm{~K})\right.$ and $A \mathrm{in}^{-1}$; $E_{\mathrm{a}}$ in $\left.\mathrm{K}\right)$. If present, the first of the two stereo-indicators refers to the carbon bearing the peroxy radical group, the second to the $>\mathrm{C}=\mathrm{C}<$ carbon atom forming the new $\mathrm{C}-\mathrm{O}$ bond. IUPAC relative stereo-indicator $\left(R^{\star}, R^{\star}\right)$ indicates the same stereo-indicator (i.e. $(R, R)$ or $(S, S))$ on both chiral carbons, and $\left(R^{*}, S^{*}\right)$ indicates differing stereo-indicators $(i . e .(R, S)$ or $(S, R))$. "Total" rate coefficients for chiral compounds assume Boltzmann equilibrium between the enantiomers

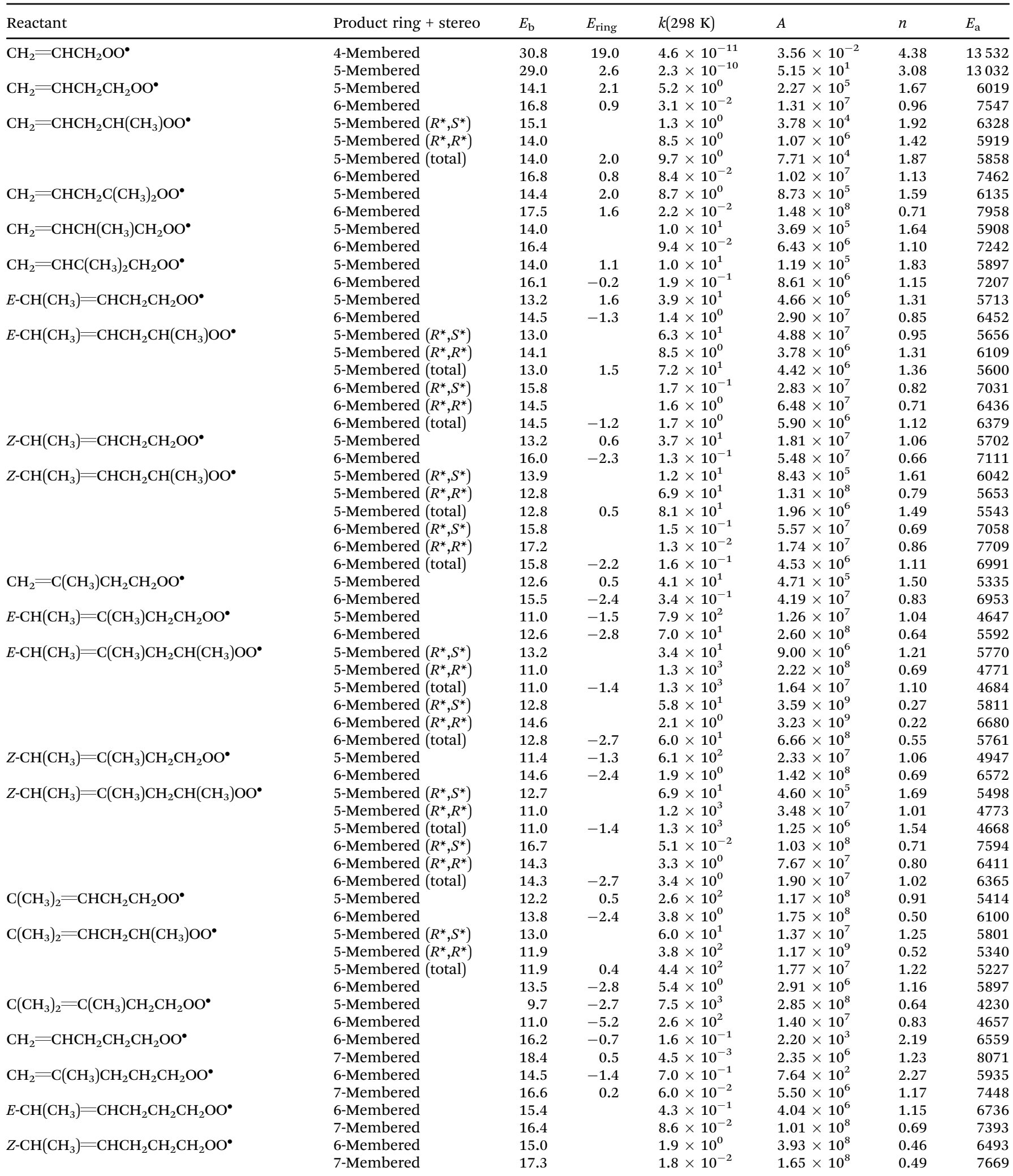


Table 1 (continued)

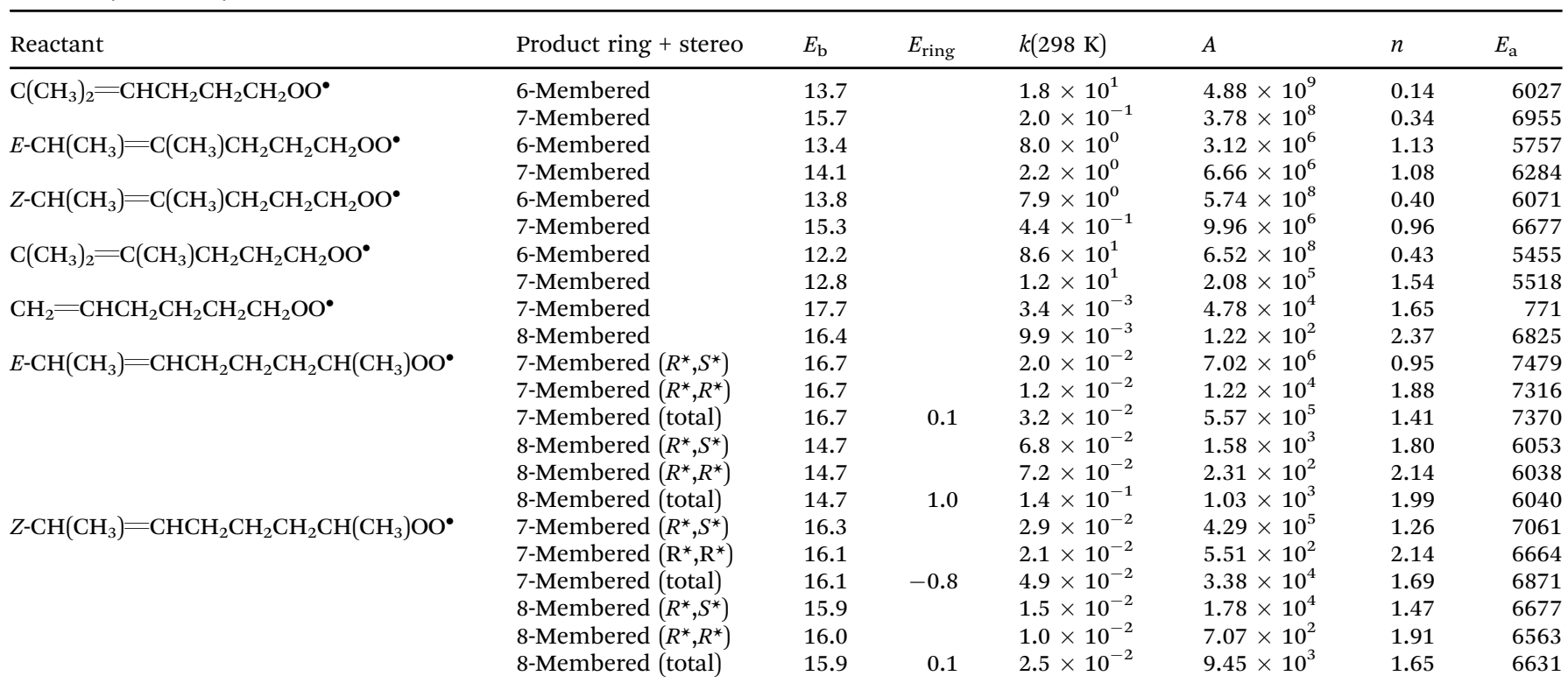

Table 2 Site- and stereo-specific ring closure reactions in oxygenated unsaturated $\mathrm{RO}_{2}$ radicals. Indicated are the barrier height $E_{\mathrm{b}}\left(\mathrm{kcal}\right.$ mol $\left.{ }^{-1}\right)$ and the rate coefficient at $298 \mathrm{~K}$ and as a Kooij expression $k(T)=A \times(T / K)^{n} \times \exp \left(-E_{\mathrm{a}} / T\right)$ for the temperature range $200-450 \mathrm{~K}(260-320 \mathrm{~K}$ for $\mathrm{Chen}$ et al.), with $k(298 \mathrm{~K})$ and $A$ in $\mathrm{s}^{-1}$ and $E_{\mathrm{a}}$ in $\mathrm{K}$. Literature data on ring closure in cyclic $\mathrm{RO}_{2}$ are not listed

\begin{tabular}{|c|c|c|c|c|c|c|c|}
\hline Reactant & Product ring & $E_{b}$ & $k(298 \mathrm{~K})$ & $A$ & $n$ & $E_{a}$ & Ref. \\
\hline $\mathrm{CH}_{2}=\mathrm{CHCH}_{2} \mathrm{C}(=\mathrm{O}) \mathrm{OO}^{\bullet}$ & $\begin{array}{l}\text { 5-Membered } \\
\text { 6-Membered }\end{array}$ & $\begin{array}{l}13.1 \\
17.4\end{array}$ & $\begin{array}{l}1.3 \times 10^{2} \\
1.1 \times 10^{-1}\end{array}$ & $\begin{array}{l}8.05 \times 10^{8} \\
3.05 \times 10^{11}\end{array}$ & $\begin{array}{r}0.65 \\
-0.16\end{array}$ & 5757 & This work \\
\hline$E-\mathrm{CH}(\mathrm{OH})=\mathrm{CHCH}_{2} \mathrm{CH}_{2} \mathrm{OO}^{\bullet}$ & 6-Membered & 17.4 & $2.8 \times 10^{1}$ & $\begin{array}{l}.05 \times 10 \\
7.15 \times 10^{9}\end{array}$ & $\begin{array}{r}-0.16 \\
0.06\end{array}$ & $\begin{array}{l}82 / 1 \\
5879\end{array}$ & $\begin{array}{l}\text { This work } \\
\text { Novelli et al. }{ }^{24}\end{array}$ \\
\hline $\mathrm{Z}-\mathrm{CH}(\mathrm{OH})=\mathrm{CHCH}_{2} \mathrm{CH}_{2} \mathrm{OO}$ & 6-Membered & 15.1 & $2.1 \times 10^{0}$ & $3.48 \times 10^{16}$ & -2.28 & 7260 & Novelli et al. ${ }^{24}$ \\
\hline$E-\mathrm{CH}(\mathrm{OH})=\mathrm{C}\left(\mathrm{CH}_{3}\right) \mathrm{CH}_{2} \mathrm{CH}_{2} \mathrm{OO}^{\bullet}$ & 6-Membered & 10.6 & $9.2 \times 10^{2}$ & $6.24 \times 10^{8}$ & 0.40 & 4689 & Novelli et $a .^{24}$ \\
\hline $\mathrm{Z}-\mathrm{CH}(\mathrm{OH})=\mathrm{C}\left(\mathrm{CH}_{3}\right) \mathrm{CH}_{2} \mathrm{CH}_{2} \mathrm{OO}^{\bullet}$ & 6-Membered & 13.0 & $7.5 \times 10^{1}$ & $2.08 \times 10^{14}$ & -1.42 & 6124 & Novelli et al. $^{24}$ \\
\hline $\mathrm{CH}_{2}=\mathrm{C}\left(\mathrm{CH}_{3}\right) \mathrm{CH}(\mathrm{OH}) \mathrm{CH}_{2} \mathrm{OO}^{\circ}$ & 6-Membered & 16.2 & $9 \times 10^{-1}$ & $1.52 \times 10^{16}$ & -1.71 & $8235^{a}$ & Vereecken and Peeters ${ }^{20}$ \\
\hline $\mathrm{CH}_{2}=\mathrm{CHC}(\mathrm{OH})\left(\mathrm{CH}_{3}\right) \mathrm{CH}_{2} \mathrm{OO}^{\bullet}$ & 6-Membered & 17.0 & $1 \times 10^{-1}$ & $1.29 \times 10^{16}$ & -1.75 & $8710^{a}$ & Vereecken and Peeters ${ }^{20}$ \\
\hline $\mathrm{Z}-\mathrm{C}\left(\mathrm{CH}_{3}\right)\left(\mathrm{CH}_{2} \mathrm{ONO}_{2}\right)=\mathrm{CHCH}_{2} \mathrm{OO}^{\bullet}$ & 5-Membered & 27.5 & $2.1 \times 10^{-9}$ & $2.07 \times 10^{9}$ & 0.42 & 13062 & Vereecken et al. $^{25}$ \\
\hline$E-\mathrm{C}\left(\mathrm{CH}_{3}\right)\left(\mathrm{CH}_{2} \mathrm{ONO}_{2}\right)=\mathrm{CHCH}_{2} \mathrm{OO}^{\bullet}$ & 5-Membered & 28.6 & $7.2 \times 10^{-11}$ & $3.43 \times 10^{4}$ & 1.90 & 13292 & Vereecken et $a .^{25}$ \\
\hline $\mathrm{CH}_{2}=\mathrm{CHC}\left(\mathrm{CH}_{3}\right)\left(\mathrm{CH}_{2} \mathrm{ONO}_{2}\right) \mathrm{OO}^{\circ}$ & 5-Membered & 26.6 & $2.2 \times 10^{-8}$ & $3.87 \times 10^{4}$ & 2.13 & 12028 & Vereecken et $a .^{25}$ \\
\hline$Z-\mathrm{CH}\left(\mathrm{CH}_{2} \mathrm{ONO}_{2}\right)=\mathrm{C}\left(\mathrm{CH}_{3}\right) \mathrm{CH}_{2} \mathrm{OO}^{\bullet}$ & 5-Membered & 27.4 & $3.1 \times 10^{-9}$ & $9.51 \times 10^{8}$ & 0.50 & 12845 & Vereecken et $a .^{25}$ \\
\hline$E-\mathrm{CH}\left(\mathrm{CH}_{2} \mathrm{ONO}_{2}\right)=\mathrm{C}\left(\mathrm{CH}_{3}\right) \mathrm{CH}_{2} \mathrm{OO}^{\bullet}$ & 5-Membered & 26.7 & $2.0 \times 10^{-9}$ & $5.01 \times 10^{7}$ & 0.74 & 12514 & ${\text { Vereecken } \text { et } a .^{25}}^{25}$ \\
\hline $\mathrm{CH}_{2}=\mathrm{C}\left(\mathrm{CH}_{3}\right) \mathrm{C}\left(\mathrm{CH}_{2} \mathrm{ONO}_{2}\right) \mathrm{OO}^{\bullet}$ & 5-Membered & 27.7 & $5.1 \times 10^{-9}$ & $1.03 \times 10^{7}$ & 1.31 & 12722 & Vereecken et al. $^{25}$ \\
\hline \multirow[t]{2}{*}{$\mathrm{CH}_{2}=\mathrm{CHC}\left(\mathrm{CH}_{3}\right)\left(\mathrm{ONO}_{2}\right) \mathrm{CH}_{2} \mathrm{OO}^{\bullet}$} & 5-Membered & 14.4 & $7.7 \times 10^{0}$ & $1.04 \times 10^{7}$ & 1.19 & 6218 & Vereecken et al. ${ }^{25}$ \\
\hline & 6-Membered & 14.7 & $2.1 \times 10^{0}$ & $2.69 \times 10^{7}$ & 0.91 & 6420 & Vereecken et $a .^{25}$ \\
\hline \multirow[t]{2}{*}{$\mathrm{CH}_{2}=\mathrm{C}\left(\mathrm{CH}_{3}\right) \mathrm{CH}\left(\mathrm{ONO}_{2}\right) \mathrm{CH}_{2} \mathrm{OO}^{\bullet}$} & 5-Membered & 13.4 & $4.1 \times 10^{1}$ & $9.60 \times 10^{9}$ & 0.12 & 5951 & Vereecken et $a .^{25}$ \\
\hline & 6-Membered & 15.7 & $1.5 \times 10^{0}$ & $2.47 \times 10^{13}$ & -1.00 & 7384 & Vereecken et $a .^{25}$ \\
\hline \multirow[t]{2}{*}{$(\mathrm{R}, \mathrm{R})-\mathrm{CH}_{2}=\mathrm{C}\left(\mathrm{CH}_{3}\right) \mathrm{CH}\left(\mathrm{C}_{2} \mathrm{H}_{3} \mathrm{O}\right) \mathrm{CH}_{2} \mathrm{CH}\left(\mathrm{C}_{2} \mathrm{H}_{3} \mathrm{O}\right) \mathrm{OO}^{\bullet}$} & 6-Membered & 14.1 & $3.9 \times 10^{0}$ & $2.73 \times 10^{-5}$ & & 4087 & Chen et al. ${ }^{27}$ \\
\hline & 7-Membered & 16.4 & $6.6 \times 10^{-1}$ & $3.62 \times 10^{-4}$ & & 5384 & Chen et $a .^{27}$ \\
\hline \multirow[t]{2}{*}{$(\mathrm{R}, \mathrm{S})-\mathrm{CH}_{2}=\mathrm{C}\left(\mathrm{CH}_{3}\right) \mathrm{CH}\left(\mathrm{C}_{2} \mathrm{H}_{3} \mathrm{O}\right) \mathrm{CH}_{2} \mathrm{CH}\left(\mathrm{C}_{2} \mathrm{H}_{3} \mathrm{O}\right) \mathrm{OO}^{\bullet}$} & 6-Membered & 15.1 & $3.0 \times 10^{0}$ & $1.75 \times 10^{10}$ & & 6568 & Chen et al. $^{27}$ \\
\hline & 7-Membered & 16.5 & $3.2 \times 10^{-1}$ & $6.22 \times 10^{10}$ & & 7609 & Chen et $_{\text {al. }}{ }^{27}$ \\
\hline $\mathrm{CH}_{2}=\mathrm{C}\left(\mathrm{CH}_{3}\right) \mathrm{CH}\left(\mathrm{C}_{2} \mathrm{H}_{3} \mathrm{O}\right) \mathrm{CH}_{2} \mathrm{CH}_{2} \mathrm{C}(=\mathrm{O}) \mathrm{CH}_{2} \mathrm{OO}^{\bullet}$ & 9-Membered & 16.2 & $3.5 \times 10^{-2}$ & $1.98 \times 10^{9}$ & & 7297 & Chen et al. $^{27}$ \\
\hline \multirow[t]{2}{*}{$(\mathrm{S}, \mathrm{S})-\mathrm{CH}_{2}=\mathrm{C}\left(\mathrm{CH}_{3}\right) \mathrm{CH}\left(\mathrm{C}_{4} \mathrm{H}_{7} \mathrm{O}\right) \mathrm{CH}(\mathrm{CHO}) \mathrm{OO}^{\circ}$} & 5-Membered & 12.8 & $2.3 \times 10^{2}$ & $1.04 \times 10^{11}$ & & 5640 & Chen et $a .^{27}$ \\
\hline & 6-Membered & 14.1 & $2.0 \times 10^{1}$ & $5.50 \times 10^{10}$ & & 6178 & Chen et $\mathrm{ll}^{27}$ \\
\hline \multirow{2}{*}{$(\mathrm{S}, \mathrm{R})-\mathrm{CH}_{2}=\mathrm{C}\left(\mathrm{CH}_{3}\right) \mathrm{CH}\left(\mathrm{C}_{4} \mathrm{H}_{7} \mathrm{O}\right) \mathrm{CH}(\mathrm{CHO}) \mathrm{OO}^{\bullet}$} & 5-Membered & 13.3 & $4.5 \times 10^{1}$ & $4.14 \times 10^{10}$ & & 5943 & Chen et $a .^{27}$ \\
\hline & 6-Membered & 16.0 & $1.4 \times 10^{0}$ & $1.88 \times 10^{11}$ & & 7440 & Chen et al. $^{27}$ \\
\hline \multirow[t]{2}{*}{$(\mathrm{S}, \mathrm{S})-\mathrm{CH}_{2}=\mathrm{C}\left(\mathrm{CH}_{3}\right) \mathrm{CH}\left(\mathrm{CH}_{3}\right) \mathrm{CH}(\mathrm{CHO}) \mathrm{OO}^{\bullet}$} & 5-Membered & 11.7 & $3.3 \times 10^{2}$ & $3.03 \times 10^{6}$ & 1.29 & 4906 & This work \\
\hline & 6-Membered & 14.4 & $1.2 \times 10^{1}$ & $1.25 \times 10^{11}$ & -0.11 & 6692 & This work \\
\hline \multirow[t]{2}{*}{$(\mathrm{S}, \mathrm{R})-\mathrm{CH}_{2}=\mathrm{C}\left(\mathrm{CH}_{3}\right) \mathrm{CH}\left(\mathrm{CH}_{3}\right) \mathrm{CH}(\mathrm{CHO}) \mathrm{OO}^{\bullet}$} & 5-Membered & 10.5 & $1.7 \times 10^{3}$ & $7.73 \times 10^{6}$ & 1.16 & 4482 & This work \\
\hline & 6-Membered & 12.8 & $4.9 \times 10^{1}$ & $2.68 \times 10^{8}$ & 0.69 & 5793 & This work \\
\hline
\end{tabular}

${ }^{a}$ Temperature-dependent rate coefficients re-evaluated from original B3LYP/6-31G(d,p) quantum chemical data and reported barrier heights.

over an order of magnitude. The strong dependence of the ring closure on the substitution pattern suggests that this reaction class will also be strongly influenced by heterosubstitution on the double bond. Novelli et al. ${ }^{24}$ calculated rates for ring closure reactions in enol- $\mathrm{RO}_{2}$ radicals, where the predicted rates (Table 2) indicate that an $\mathrm{OH}$ group enhances the reaction rate by an order of magnitude compared to a methyl group. 


\subsection{Substituents adjacent to the peroxy radical moiety}

The presence of alkyl groups adjacent to the peroxy radical moiety has comparatively little influence. For ring closure to 5- or 6-membered rings, we find the spread of the rate coefficients for primary, secondary, and tertiary alkylperoxy radicals to be within a factor of four at $298 \mathrm{~K}$, i.e. the rate coefficients are within a factor of two of the averaged rate coefficient for $-\mathrm{CH}_{2} \mathrm{OO}{ }^{\bullet}$, $-\mathrm{CHCH}_{3} \mathrm{OO}$, and $-\mathrm{C}\left(\mathrm{CH}_{3}\right)_{2} \mathrm{OO}^{\circ}$ moieties. This is in strong contrast to e.g. H-migration in $\mathrm{RO}_{2}$ radicals, where the impact of alkyl substitution around the peroxy radical moiety on the reaction rate can exceed a factor $20 .^{11}$

The small impact of alkyl substitution around the radical moiety allows for a significant reduction of the complexity of the SAR, and concomitantly the needed number of calculations to derive the SAR. For larger molecules, we have thus only explicitly characterized the $-\mathrm{CH}_{2} \mathrm{OO}^{\bullet}$ moieties, and derive the SAR to predict the expected average across primary, secondary, and tertiary peroxy radicals.

The oxo group in acylperoxy radicals, $-\mathrm{C}(=\mathrm{O}) \mathrm{OO}^{\bullet}$, was reported to accelerate $\mathrm{RO}_{2}$ radical H-migration reactions by an order of magnitude. ${ }^{11,43,44}$ Exploratory calculations on acylperoxy radicals (Table 2) indicate that the acyl group also accelerates ring closure by up to a factor 25 .

\subsection{Spectator substituents}

The scarce data in Table 1 suggests that substituents on carbons not implanted on the double bond or the carbon bearing the peroxy radical group have only a moderate impact on the predicted rate coefficients. As a first approximation, it appears one can consider substituents away from the active sites as spectators, and ignore their impact on the reaction. It is currently unclear whether longerrange effects such as H-bonding or strong electron-donating/withdrawing groups can invalidate this simplification. Vereecken and Peeters $^{20}$ reported ring closure reactions in isoprene-derived unsaturated $\mathrm{RO}_{2}$ radicals with spectator $\mathrm{OH}$-substitutions. Despite the much lower level of theory in that study, the predicted rate coefficients are within a factor 3 of the current predictions for $\mathrm{RO}_{2}$ when ignoring the $\mathrm{OH}$ spectator, bringing further support for the low impact of spectator substituents. The results by Vereecken et $a .^{25}$ on nitrate-substituted $\mathrm{RO}_{2}$ radicals also partially support the low impact of spectator groups. However, one 6-membered ring closure with a nitrate group shows a larger difference of a factor of 50 relative to the non-oxygenated $\mathrm{RO}_{2}$ studied in this work. Data on $\beta$-carbonyl-substituted $\mathrm{RO}_{2}$ radicals by us and by Chen et al. ${ }^{27}$ (see Table 2) likewise suggests an impact of over an order of magnitude. Finally, some unsaturated $\mathrm{RO}_{2}$ radicals with a second unsaturation in $\beta$-position to the peroxy radical, $\mathrm{CH}_{2}=\mathrm{CH}-\mathrm{C}\left(=\mathrm{CH}_{2}\right) \mathrm{CH}_{2} \mathrm{OO}^{\bullet}$, are reported to be less reactive ${ }^{26}$ towards ring closure than suggested by the SAR. Our current treatment of spectator groups may thus be too simplified and further work on the impact of substituents is needed to refine the SAR.

\subsection{Structure-activity relationship}

The reactivity trends described above are used to derive a structure-activity relationship for ring closure in unsaturated
$\mathrm{RO}_{2}$ radicals with aliphatic substituents. The reaction rates are considered to be mainly determined by ring size, site-specificity on the double bond, and substitution on the double bond. Compared to the uncertainty of the predictions, the impact of other substituents is considered to be not yet sufficiently clear to warrant a more complex SAR with additional parameters at this time. Finally, we assume that the impact of an alkyl group is not strongly dependent on the length of the substituent alkyl chain, as was already found in SARs for other reaction classes. ${ }^{4,11,25,45,46}$

For ring closure on the inner carbon of the double bond, the stereo-specificity on the outer double bonded carbon has little influence and is not considered explicitly in the SAR. For these reactions, the reactivity trend prediction could potentially be even further simplified by considering only 4 template categories, i.e. a double bond with $0,1,2$ or 3 additional alkyl substituents. However, this reduction does not work well for ring closure on the outer carbon, where the stereo-substitution and positioning of the substituents have a larger impact. To keep the SAR setup similar for both types of ring closure, we choose at this time to use categories with site-specific substitution on the double bond for both closures. This will also aid in future extensions to oxygenated compounds, where the impact of sitespecificity is likely to be more pronounced.

Table 3 summarizes the SAR as a lookup table, listing room temperature $k(298 \mathrm{~K})$ and rate coefficients $k(T)$ for $T=200-$ 450 K. Fig. 1 compares the explicit rate predictions in Table 1 against the SAR predictions; to our knowledge there are no direct experimental data available against which we can validate the SAR. The SAR captures the reactivity trends in the source data well (goodness of fit). Considering the uncertainty on the theoretical source data (of the order of a factor 3 to 5), and the uncertainty caused by omitting some of the minor influences on the rate coefficient, we estimate an overall uncertainty on the SAR predictions of a factor of 10 for aliphatic unsaturated $\mathrm{RO}_{2}$. For oxygenated $\mathrm{RO}_{2}$, Table 2 suggests that the deviation can be significantly larger, and care should be taken when trying to apply the SAR outside its field of applicability.

\section{Subsequent chemistry of the cycloperoxide alkyl product radicals}

In general, two reaction routes are accessible for the cycloperoxide alkyl radicals formed after ring closure. The first is recombination with $\mathrm{O}_{2}$, forming a cycloperoxide peroxy radical (called cycOO- $\mathrm{RO}_{2}$ hereafter). The rate coefficient for alkyl $+\mathrm{O}_{2}$ recombination reactions has been measured to be $10^{-12}$ to $10^{-11} \mathrm{~cm}^{3}$ molecule ${ }^{-1} \mathrm{~s}^{-1},{ }^{47}$ which under atmospheric conditions yields a pseudo-first order rate coefficient of $\sim 10^{7} \mathrm{~s}^{-1}$. An alternative reaction (R3) is re-arrangement to an epoxide and an alkoxy radical:

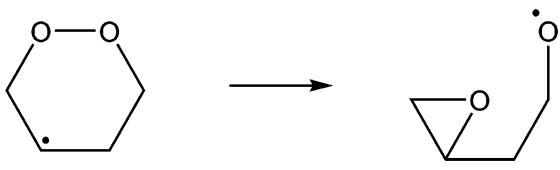


Table 3 Structure-activity relationship for ring closure reactions in unsaturated $\mathrm{RO}_{2}$ radicals forming 5- to 8-membered rings, for various substitutions on the double bond $\left(\mathrm{CH}_{3}\right.$ is considered equivalent to an alkyl chain of any length). Indicated are the barrier height $E_{\mathrm{b}}\left(\mathrm{kcal} \mathrm{mol}{ }^{-1}\right)$ and the rate coefficient at $298 \mathrm{~K}$ and as a Kooij expression $\mathrm{k}(200-450 \mathrm{~K})=A \times(T / \mathrm{K})^{n} \times \exp \left(-E_{\mathrm{a}} / T\right)\left(\mathrm{k}(298 \mathrm{~K})\right.$ and $A$ in $\mathrm{s}^{-1}$; $E_{\mathrm{a}}$ in $\left.\mathrm{K}\right)$. Ring closure in $\beta$-unsaturated $\mathrm{RO}_{2}$ is slow and not competitive

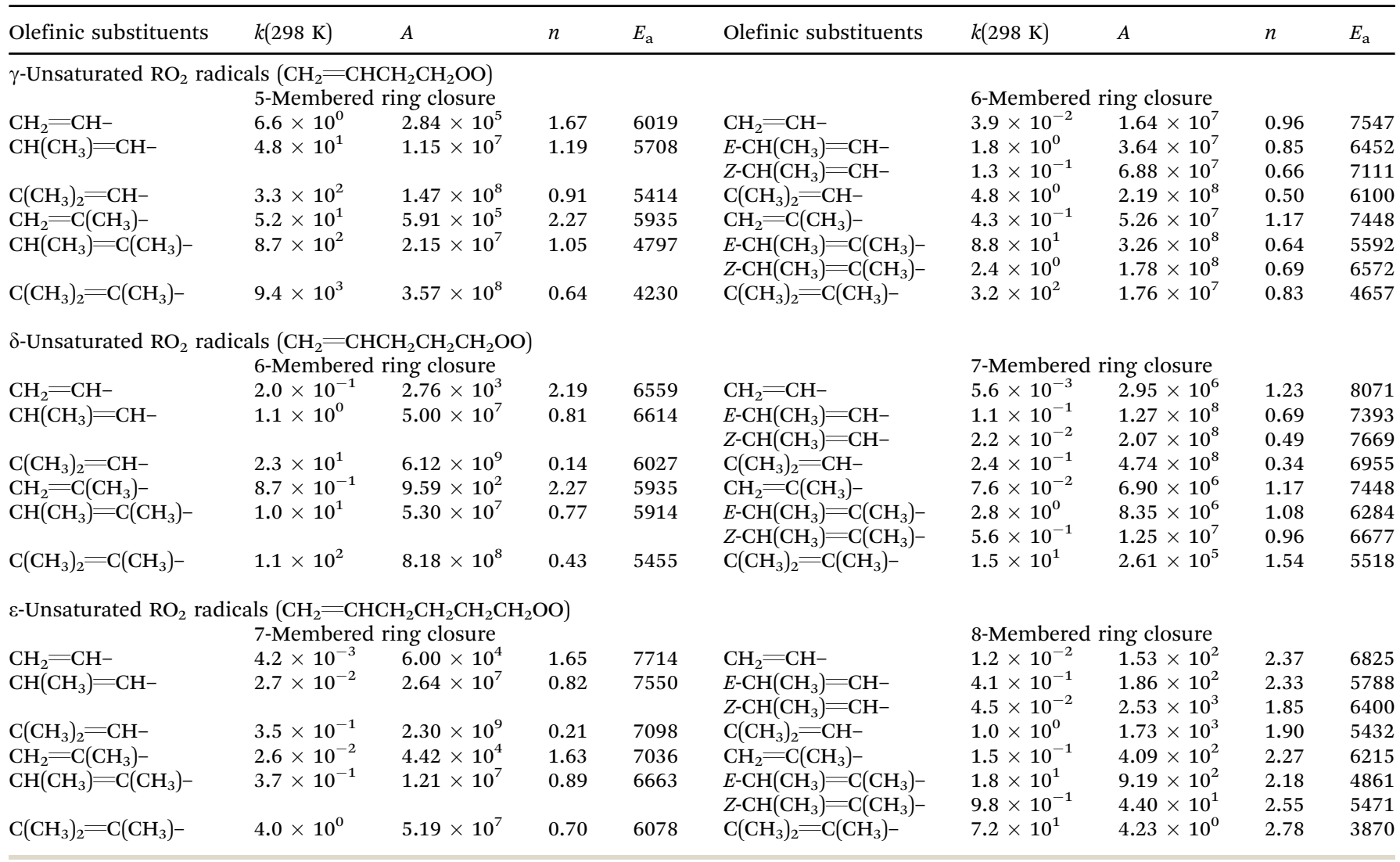

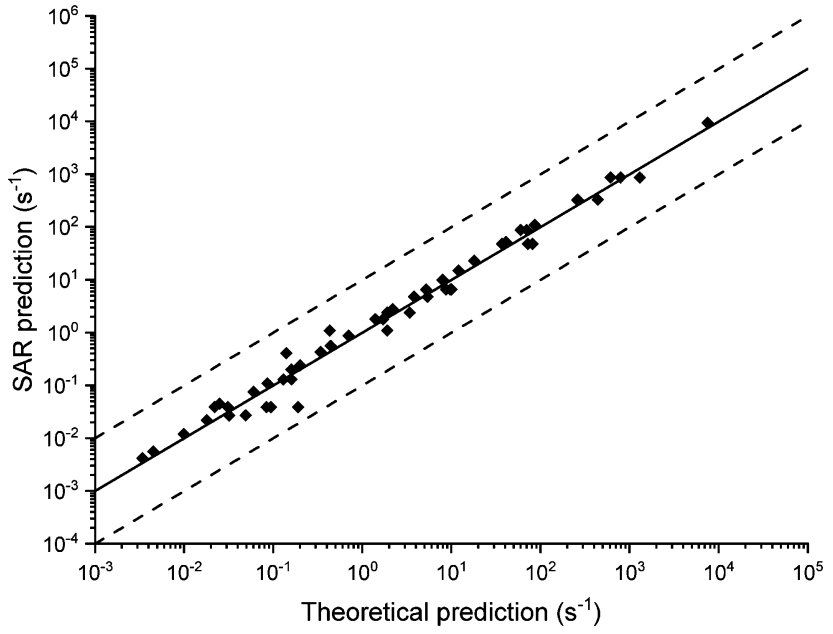

Fig. 1 Goodness of fit for the structure-activity relationship relative to the calculated (total) rate coefficients in Table 1. The solid line depicts 1:1 correspondence, the dashed lines delineate a factor of 10 uncertainty.

These rearrangements have been theoretically characterized by Møller et $a l^{48}$ to have high reaction barriers of 13 to $17 \mathrm{kcal} \mathrm{mol}^{-1}$ for the substitution patterns in this work, and Vereecken and Peeters ${ }^{20}$ argue that the geometric constraints caused by the ring structure will further hamper this reaction, with a calculated energy barrier exceeding $25 \mathrm{kcal} \mathrm{mol}^{-1}$ for a 6-membered ring. The theoretical work by Møller et al. ${ }^{48}$ predicts rate coefficients $<10^{2} \mathrm{~s}^{-1}$ for non-cyclic non-oxygenated $\beta$-hydroperoxy alkyl radicals, making epoxide-alkoxy radical formation negligible compared to $\mathrm{O}_{2}$ addition under atmospheric conditions. For multi-substituted $\beta$-hydroperoxy alkyl radicals, however, rates as high as $10^{7}$ to $10^{10} \mathrm{~s}^{-1}$ are predicted, which would dominate recombination with $\mathrm{O}_{2}$. Møller et al. summarize the structural requirements for fast epoxidation reactions, concluding that an $\mathrm{OH}$ group is needed on the alkyl radical site, and another oxygenated group. For ring closure reactions, this implies that epoxidation would only be important for $\mathrm{RO}_{2}$ with a double bond carrying an $\mathrm{OH}$ substituent (i.e. an enol) and simultaneously another oxygenated group on the other carbon of the double bond. Such substitution patterns make up only a very small fraction of the atmospherically relevant unsaturated $\mathrm{RO}_{2}$ radicals, and are not considered further at this time.

\section{H-Migration in the product cycloperoxide-alkylperoxy radicals}

To study the subsequent fate of the cycOO- $\mathrm{RO}_{2}$ radicals, we examined the migration of $\mathrm{H}$-atoms implanted on the cycloperoxide 
ring towards the radical oxygen. CycOO- $\mathrm{RO}_{2}$ radicals formed from unsaturated $-\mathrm{RO}_{2}$ by ring closure on the outer olefinic carbon have the peroxy radical group implanted directly on the ring, while ring closure on the inner carbon has the peroxy group on the first carbon of a ring substituent. One should also distinguish between migration of an aliphatic $\mathrm{H}$-atom, versus abstraction of an $\mathrm{H}$-atom adjacent to the peroxide functionality. ${ }^{11}$ As already shown earlier, product radicals with an $\alpha$-OOR alkyl radical site are unstable, ${ }^{49,50}$ and the peroxide ring can be expected to break after such H-migrations. At this time, we do not quantify the impact of substituents on H-migration, though it is briefly discussed below.

\subsection{Reactivity trends}

The barrier heights and rate coefficients for migrations of $\mathrm{H}$-atoms on the cycloperoxide ring to the peroxy radical radical site are provided in Table 4, while some molecular variations are listed in Table 5. 1,3- and 1,4-H-migrations have too high a barrier ${ }^{11}$ and are not considered. The accessible $\mathrm{H}$-atoms are all on the same side as the peroxy radical moiety (syn side), except for a few structures where 1,5-shift of anti-H-atoms is geometrically accessible. H-Migration of an $\alpha$-OOR $\mathrm{H}$-atom, i.e. next to the peroxide functionality in the ring, leads to ring breaking forming a carbonyl-alkoxy radical with an energy 35 to $40 \mathrm{kcal} \mathrm{mol}{ }^{-1}$ below the cycOO- $\mathrm{RO}_{2}$. In most cases this ring breaking is spontaneous, but for cycOO- $\mathrm{RO}_{2}$ with the $-\mathrm{OO}^{\bullet}$ peroxy group implanted on the ring, our current level of theory suggests that the $\alpha$-OOR alkyl radical product may have a very shallow potential energy well. We have not examined whether this is an artifact of the methodology, as breaking of the ring is clearly much faster than any competing reactions, including $\mathrm{O}_{2}$ addition on the radical site, rendering the issue moot. Except for the formation of carbonyl-alkoxy radicals by migration of $\alpha$-OOR $\mathrm{H}$-atoms and their subsequent fragmentation, all alkyl radical products formed in the reactions studied here are expected to rapidly recombine with $\mathrm{O}_{2}$, forming a new cyclic $\mathrm{RO}_{2}$ with the radical moiety implanted directly on the ring.

The rate of reaction can be seen to be strongly dependent on the size of the ring, the position of abstraction in that ring, and the span of the H-migration. Compared to similar H-migrations in non-cyclic hydrocarbons, ${ }^{10,11}$ the predicted rate varies by as much as 2 orders of magnitude due to the differences in ring strain, barrier height and tunneling. Fig. 2 shows the ratio $k_{\text {cyclic }}(T) / k_{\text {noncyclic }}(T)$ of the predicted rates for the cycOO- $\mathrm{RO}_{2}$ (Table 4) over the predictions by the SAR by Vereecken and Nozière, ${ }^{11}$ where we used the SAR-predicted rate of $\alpha$-OOH-substituted $\mathrm{H}$-atoms as a proxy for the $\alpha$-OOR $\mathrm{H}$-atoms in the cycOO- $\mathrm{RO}_{2}$, and where the SAR predictions were corrected by a factor of 2 to account for the inaccessible anti-H-atoms. As can be seen, the cycOO- $\mathrm{RO}_{2}$ have significantly different rate

Table 4 Site- and stereo-specific $\mathrm{H}$-migration reactions in cycloperoxide-alkylperoxy radicals $\left(\mathrm{cycOO}-\mathrm{RO}_{2}\right)$. Indicated are the barrier height $E_{\mathrm{b}}(\mathrm{kcal}$ $\mathrm{mol}^{-1}$ ) and relative energy of the product $E_{\text {product }}\left(\mathrm{kcal} \mathrm{mol}^{-1}\right)$ at the CCSD(T)//M06-2X-D3 level of theory (products at M06-2X/aug-cc-pVTZ level of theory), as well as the rate coefficient at $298 \mathrm{~K}$ and as a Kooij expression $k(200-450 \mathrm{~K})=A \times(T / K)^{n} \times \exp \left(-E_{\mathrm{a}} / T\right)\left(\mathrm{K}(298 \mathrm{~K})\right.$ and $A$ in s ${ }^{-1} ; E_{\mathrm{a}}$ in $\left.\mathrm{K}\right)$

\begin{tabular}{|c|c|c|c|c|c|c|c|}
\hline Reactant & H-migration span & $E_{\mathrm{b}}$ & $E_{\text {product }}$ & $k(298 \mathrm{~K})$ & $A$ & $n$ & $E_{\mathrm{a}}$ \\
\hline $\mathrm{CH}_{2} \mathrm{OO}^{\circ}$ & $\begin{array}{l}1,5-\mathrm{H}_{\mathrm{a}}(\text { syn-side }) \\
1,6-\mathrm{H}_{\mathrm{b}} \\
1,7-\mathrm{H}_{\mathrm{c}}(\alpha \text {-peroxide })\end{array}$ & $\begin{array}{l}24.5 \\
25.0 \\
26.2\end{array}$ & $\begin{array}{r}14.1 \\
13.6 \\
-34.6\end{array}$ & $\begin{array}{l}2.5 \times 10^{-5} \\
5.0 \times 10^{-6} \\
1.9 \times 10^{-5}\end{array}$ & $\begin{array}{l}2.92 \times 10^{-29} \\
1.55 \times 10^{-33} \\
1.73 \times 10^{-113}\end{array}$ & $\begin{array}{l}12.84 \\
13.91 \\
39.78\end{array}$ & $\begin{array}{r}5370 \\
4735 \\
-6613\end{array}$ \\
\hline$\gamma-00^{\circ}$ & $\begin{array}{l}1,5-\mathrm{H}_{\mathrm{a}} \\
1,6-\mathrm{H}_{\mathrm{b}}(\alpha \text {-peroxide })\end{array}$ & $\begin{array}{l}24.2 \\
28.3\end{array}$ & $\begin{array}{l}13.8 \\
15.2^{a}\end{array}$ & $\begin{array}{l}4.5 \times 10^{-5} \\
2.0 \times 10^{-7}\end{array}$ & $\begin{array}{l}1.54 \times 10^{-27} \\
1.03 \times 10^{-39}\end{array}$ & $\begin{array}{l}12.23 \\
16.12\end{array}$ & $\begin{array}{l}5340 \\
5219\end{array}$ \\
\hline$\succ-00^{\circ}$ & $\begin{array}{l}1,5-\mathrm{H}_{\mathrm{a}} \\
1,6-\mathrm{H}_{\mathrm{b}} \\
1,7-\mathrm{H}_{\mathrm{c}}(\alpha \text {-peroxide })\end{array}$ & $\begin{array}{l}25.1 \\
26.2 \\
26.3\end{array}$ & $\begin{array}{l}13.9 \\
15.6 \\
11.2^{a}\end{array}$ & $\begin{array}{l}2.1 \times 10^{-5} \\
4.3 \times 10^{-6} \\
3.1 \times 10^{-6}\end{array}$ & $\begin{array}{l}1.65 \times 10^{-31} \\
5.50 \times 10^{-23} \\
1.17 \times 10^{-48}\end{array}$ & $\begin{array}{l}13.64 \\
10.54 \\
18.73\end{array}$ & $\begin{array}{l}5241 \\
6308 \\
2688\end{array}$ \\
\hline
\end{tabular}

${ }^{a}$ The $\alpha$-OOR alkyl radical has a very small barrier to decomposition at the current level of theory. 
Table 5 Site- and stereo-specific $\mathrm{H}$-migration reactions in structural variations of cyc- $\mathrm{RO}_{2}, \mathrm{cycOO}-\mathrm{RO}_{2}$ and cycOO-RO radicals; these compounds may not have any atmospheric formation pathway. Indicated are the barrier height $E_{\mathrm{b}}\left(\mathrm{kcal} \mathrm{mol}^{-1}\right)$ and relative energy of the product $E_{\mathrm{product}}\left(\mathrm{kcal}\right.$ mol ${ }^{-1}$ ) at the CCSD(T)//M06-2X-D3 level of theory (products at M06-2X-D3/aug-cc-pVTZ level of theory), as well as the rate coefficient at $298 \mathrm{~K}$ and as a Kooij expression $k(200-450 \mathrm{~K})=A \times(T / K)^{n} \times \exp \left(-E_{\mathrm{a}} / T\right)\left(k(298 \mathrm{~K})\right.$ and $A$ in $\mathrm{s}^{-1} ; E_{\mathrm{a}}$ in $\left.\mathrm{K}\right)$

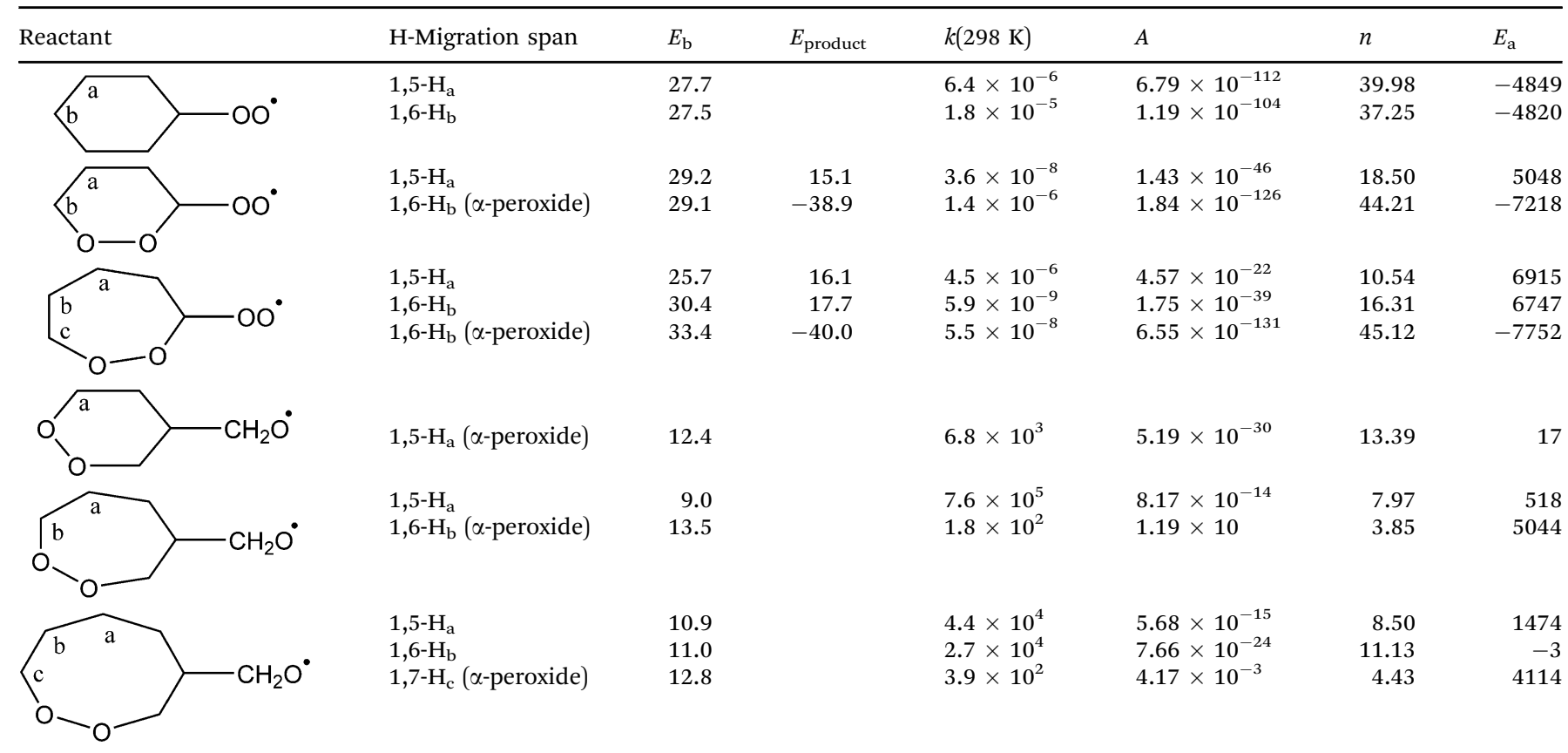

coefficients than non-cyclic $\mathrm{RO}_{2}$, where especially below $350 \mathrm{~K}$ the rate coefficient ratio is strongly temperature dependent due to the differences in energy, entropy, and tunneling between cyclic and non-cyclic $\mathrm{RO}_{2}$. Even within a specific reaction class, the ratio $k_{\text {cyclic }}(T) / k_{\text {noncyclic }}(T)$ varies significantly, with e.g. 1,5- or 1,6- $\mathrm{H}$-migration rates in cycloperoxide- $\mathrm{CH}_{2} \mathrm{OO}{ }^{\bullet}$ radicals being significantly faster, about similar, or significantly slower than their non-cyclic counterpart (Fig. 2). Likewise, the temperaturedependence of the ratio is very different between $\alpha-\mathrm{OOR}-1,6-\mathrm{H}-$ migrations compared to $\alpha$-OOR-1,7-H-migrations. For cycloperoxide$\mathrm{OO}^{\bullet}$ radicals, there can be many orders of magnitude difference between the rates at the lower temperatures, even within a given
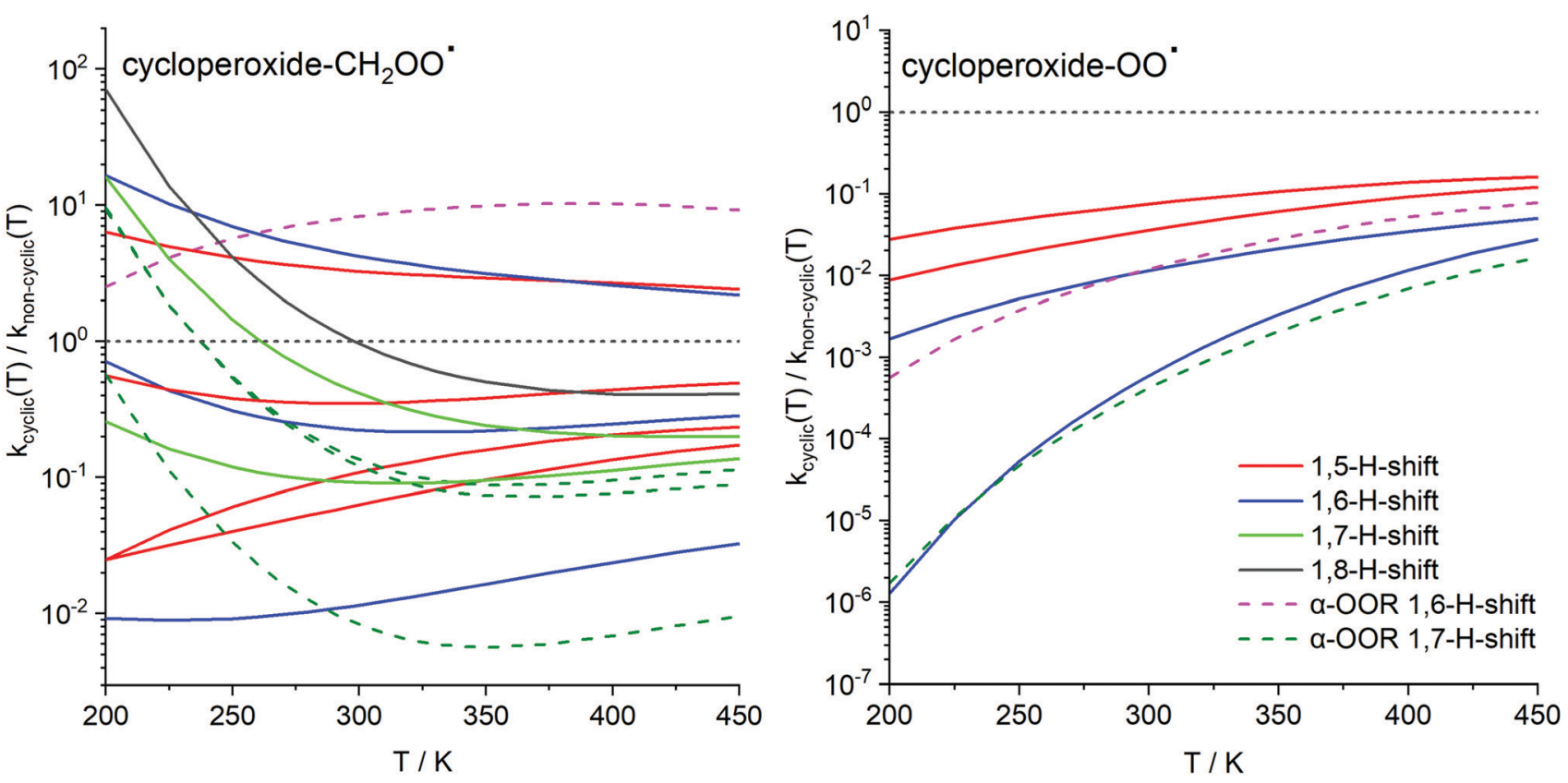

Fig. 2 Ratio of the rate coefficient for $\mathrm{H}$-migration in cycloperoxide- $\mathrm{RO}_{2}$ radicals against SAR-predictions ${ }^{11}$ for analogous $\mathrm{H}$-migrations in oxygenated non-cyclic $\mathrm{RO}_{2}$. Dashed line: 1:1 correspondence. Left panel: $-\mathrm{CH}_{2} \mathrm{OO} \bullet$ radical site implanted on the ring. Right panel: Peroxy radical $-\mathrm{OO}^{\bullet}$ implanted directly on the ring. 
reaction class. Hence, while on average the rate coefficients for cycOO- $\mathrm{RO}_{2}$ are only a factor $\sim 4$ below those of non-cyclic $\mathrm{RO}_{2}$, the large scatter of a factor 25 indicates that reactivity trends are not transferable between cyclic and non-cyclic $\mathrm{RO}_{2}$.

To investigate the impact of the peroxide group in the ring, we examined some molecular isomers of the cycOO- $\mathrm{RO}_{2}$ radicals, shown in Table 5; note that these compounds can not be formed by the mechanism of $\mathrm{RO}_{2}$ ring closure described above, and these structures may not even have atmospheric formation channels. The position of the peroxide group in the ring changes which $\mathrm{H}$-migration spans lead to an $\alpha$-OOR radical product, which directly affects the rate of reaction. Comparing the data from Table 4 against Table 5, we also find an order of magnitude difference in rate for the 1,5-alkyl-H-migration out of a seven-membered ring that differs only in the position of the (remote) peroxide group, indicating that the position of the peroxide group affects the barrier height even if not directly involved in the reaction. Comparing against a cyclohexylperoxy radical, we find that the corresponding 6-membered cycloperoxide-peroxy radical isomers both have higher barrier heights, likely caused by the increased ring strain induces by the different bond lengths and bond angles around the endo-cyclic oxygen atoms. We conclude that the presence of a peroxide functionality, and its precise position in the ring, can have a large impact on the reaction rate; at the present time we do not have sufficient data to systematically characterize such influence.

\subsection{Towards a structure-activity relationship}

The ratios shown in Fig. 2 do not show a correlation with ring size or migration span that can be used to derive an easily quantifiable trend. As such, it does not appear feasible to build an SAR for migration of $\mathrm{H}$-atoms implanted on the ring of cycOO- $\mathrm{RO}_{2}$ based on the reactivity trends for non-cyclic $\mathrm{RO}_{2}$, at least not below $\sim 400 \mathrm{~K}$. At this moment we also don't have enough data available to fully examine the impact of the position of the two O-atoms in the ring, or to quantify the impact of substituents. We surmise that an additional $\alpha$-alkyl, $\alpha-\mathrm{OH}$ or $\alpha-\mathrm{OOH}$ substituent would have a similar impact on cyclic $\mathrm{RO}_{2}$ as in aliphatic $\mathrm{RO}_{2} \cdot{ }^{11}$ Such a substituent must be in anti-position to avoid blocking $\mathrm{H}$-migration, i.e. stereo-specificity must be rigorously accounted for. In contrast, reactivity trends ${ }^{11}$ for e.g. double bonds or carbonyl groups which affect ring strain and require the appropriate relative orientation to allow allylic/vinoxy stabilization of the product radical, will likely never be transferable between cyclic and non-cyclic $\mathrm{RO}_{2}$. As migration of $\mathrm{H}$-atoms implanted on the ring appears on average slower than in non-cyclic $\mathrm{RO}_{2}$, one should consider that $\mathrm{H}$-abstraction from the (oxygenated) substituents, if present, instead of from the ring itself could be the more favorable pathway. If so, a useful SAR for cyclic $\mathrm{RO}_{2}$ must be based on an extensive set of data on substituted rings, which is outside the scope of this paper. Finally, we note that the slow H-migration pathways could make bimolecular loss processes dominant; this includes reaction with $\mathrm{R}^{\prime} \mathrm{O}_{2}$, $\mathrm{HO}_{2}, \mathrm{NO}, \mathrm{NO}_{2}, \mathrm{NO}_{3}, \mathrm{OH}$, etc. For many of these processes, predictive structure-activity relationships are available..$^{51-53}$

\section{Fate of cycloperoxide-alkoxy radicals}

Given the rather slow reaction rates of autoxidation predicted above for the product cycOO- $\mathrm{RO}_{2}$ radicals, they have a higher

Table 6 Site- and stereo-specific $\mathrm{H}$-migration reactions in cycloperoxide-alkoxy radicals (cycOO-RO). Indicated are the barrier height $E_{\mathrm{b}}\left(\mathrm{kcal}\right.$ mol ${ }^{-1}$ ) at the CCSD(T)//M06-2X-D3 level of theory (products at M06-2X-D3/aug-cc-pVTZ level of theory), as well as the rate coefficient at $298 \mathrm{~K}$ and as a Kooij expression $k(200-450 \mathrm{~K})=A \times(T / K)^{n} \times \exp \left(-E_{\mathrm{a}} / T\right)\left(k(298 \mathrm{~K})\right.$ and $A$ in $\mathrm{s}^{-1} ; E_{\mathrm{a}}$ in $\left.\mathrm{K}\right)$

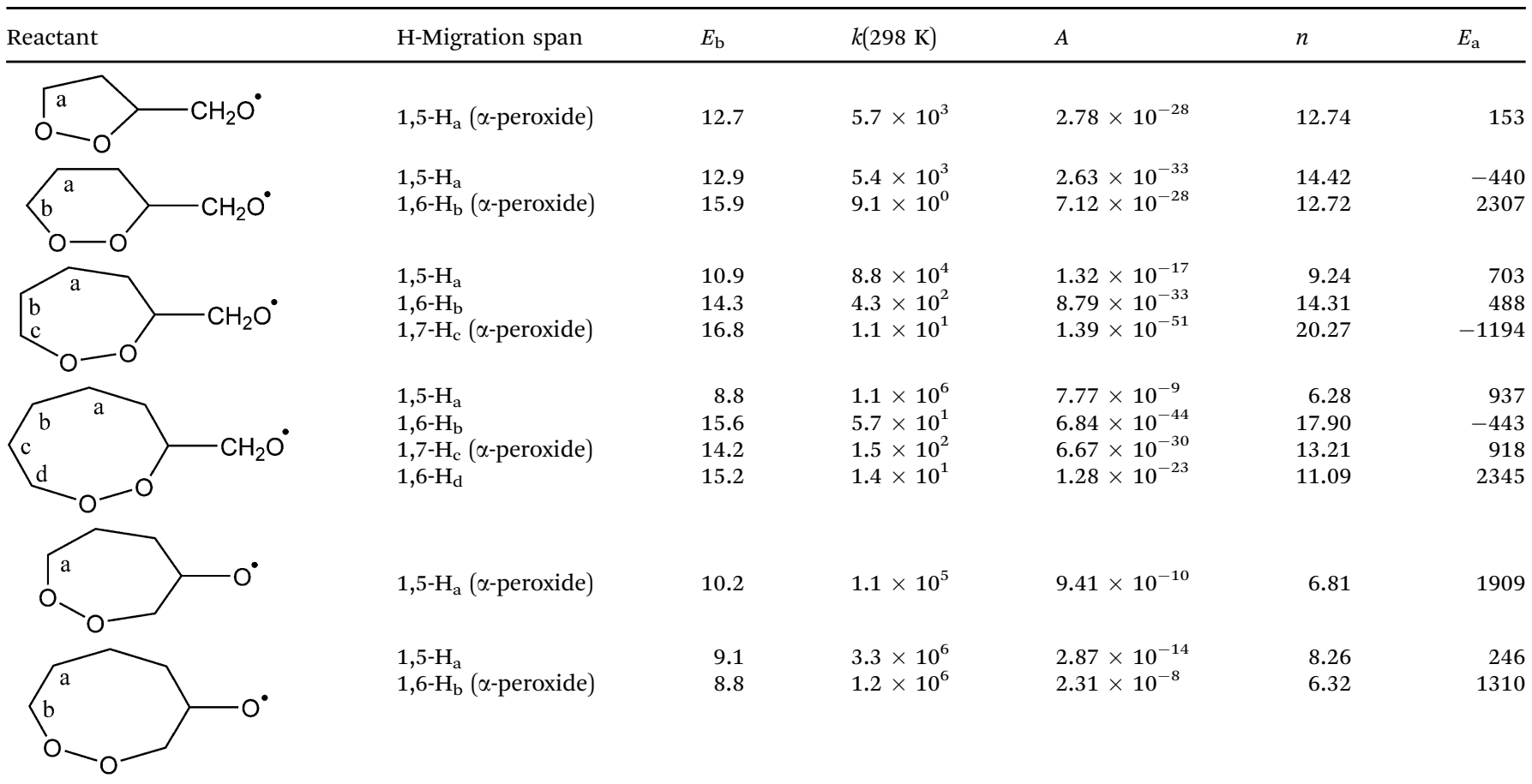


likelihood of undergoing bimolecular reactions than non-cyclic $\mathrm{RO}_{2}$. In their reaction with $\mathrm{R}^{\prime} \mathrm{O}_{2}, \mathrm{HO}_{2}, \mathrm{OH}, \mathrm{NO}$, or $\mathrm{NO}_{3}$ radicals, this would (partially) lead to the formation of cycloperoxidealkoxy radicals, called cycOO-RO radicals henceforth. Alkoxy radicals with a sufficiently long chain can undergo fast $\mathrm{H}$-migration or decomposition reactions, with rate coefficients often exceeding the rate of reaction with $\mathrm{O}_{2}$ by several orders of magnitude. ${ }^{45,54,55}$ For the compounds studied here, the main competition for the fate of the cycOO-RO radicals would be between $\mathrm{H}$-migration and decomposition, with $\mathrm{HO}_{2}$ formation by reaction with $\mathrm{O}_{2}$ being too slow. ${ }^{54}$ To assess the impact of $\mathrm{H}$-migration and hence further autoxidation in cycOO-RO radicals, we present a set of calculations in Table 6 for alkoxy radicals derived from $\mathrm{RO}_{2}$ ring closure reactions, as well as some structural variations in Table 5. The rate coefficients for migration of $\mathrm{H}^{-}$ atoms on the ring, below $10^{4} \mathrm{~s}^{-1}$ for most H-migrations studied, are somewhat low compared to those in non-cyclic alkoxy radicals; for comparison, the 1,5-H-shift in 1-butoxy has a rate coefficient of $\sim 3 \times 10^{5} \mathrm{~s}^{-1} \cdot{ }^{40,55-57}$ The lower rates are mostly due to the increased ring strain in the bicyclic transition state, exacerbated by the position of the radical oxygen implanted either directly on the ring or with only 1 intervening carbon. Consequently, the highest rates were found for the largest rings and hence lowest ring strain. We have not investigated the impact of substituents, but the H-migration SAR by Vereecken and Peeters ${ }^{45}$ may offer some transferable information on the impact of substituents, e.g. for $\alpha-\mathrm{OH}$ substituents. Similar to $\mathrm{H}$-migration in cyc- $\mathrm{RO}_{2}$ radicals, we surmise that H-migration from any (oxygenated) substituents, if present, may be more favorable than from the carbons in the cycle, but did not explore this further. The H-migration is followed by $\mathrm{O}_{2}$ addition under atmospheric conditions, forming a hydroxyperoxyradical.

For the alternative fate by decomposition, rates for cycOO$\mathrm{RO}$ are expected to be well predicted by the SAR by Vereecken and Peeters, ${ }^{58}$ and its recent update in Novelli et al. ${ }^{59}$ this SAR includes the impact of the ring. For the cycOO-RO in Table 6 that decompose by $\mathrm{CH}_{2} \mathrm{O}$ elimination, barrier heights $\leq 7.5 \mathrm{kcal} \mathrm{mol}^{-1}$ and rates $k(298 \mathrm{~K}) \geq 8 \times 10^{7} \mathrm{~s}^{-1}$ are predicted, while cycOO-RO with the radical O-atom implanted on the ring preferentially break the ${ }^{\bullet} \mathrm{OC}-\mathrm{COO}$ bond, with SAR-predicted barriers of $\leq 8.5 \mathrm{kcal} \mathrm{mol}^{-1}$ and $k(298 \mathrm{~K}) \geq 1 \times 10^{7} \mathrm{~s}^{-1}$. In both cases, an $\alpha$-OOR alkyl radical is formed, which are known to decompose without (significant) barrier to a carbonyl and an alkoxy radical; ${ }^{49,50}$ both classes of cycOO-RO in Table 6 will thus lead to two fragments: HCHO and a non-cyclic carbonylalkoxy radical, as shown below.

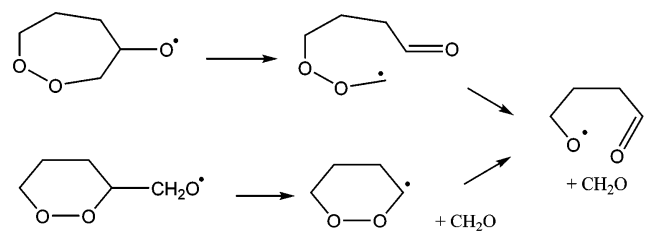

Given the high rate of decomposition compared to H-migration in cycOO-RO, the main fate of most cycOO-RO in Table 6 is fragmentation and decyclization of the ring originally formed in the unsaturated $\mathrm{RO}_{2}$ ring closure. Only for the largest rings studied, where ring strain in the H-migration TS is lowest, $\mathrm{H}$-migration may contribute for a non-negligible fraction.

Comparing the data for cycOO-RO radical isomers different only by the position of the peroxide group in the ring (Tables 5 and 6), we find that the site-specificity of the peroxide group can affect the rate coefficient by over an order of magnitude, with sometimes large differences in barrier height for otherwise comparable processes. As for the $\mathrm{H}$-migration in cycOO- $\mathrm{RO}_{2}$ radicals, we thus conclude that the rate coefficients are isomer-specific and do not readily generalize to generic cycloperoxides.

\section{Conclusions}

The ring closure reaction in aliphatic mono-unsaturated $\mathrm{RO}_{2}$ radicals was examined by theoretical calculations, and a SAR was formulated to predict rate coefficients for use in mechanism development. From these calculations and SAR, we found that ring closure reactions in unsaturated $\mathrm{RO}_{2}$ radicals are fast, exceeding $1 \mathrm{~s}^{-1}$ for many substitution patterns and ring sizes. These reactions are typically faster than aliphatic $\mathrm{RO}_{2} \mathrm{H}$-migrations and comparable in rate to $\mathrm{RO}_{2}$ allylic $\mathrm{H}$-migrations, and should readily compete with bimolecular reactions of $\mathrm{RO}_{2}$ even at moderately elevated concentrations of $\mathrm{NO}, \mathrm{HO}_{2}$, and $\mathrm{RO}_{2}$. The cyclic peroxide alkyl radical products are expected to recombine with $\mathrm{O}_{2}$ in the atmosphere, forming cycloperoxide $\mathrm{RO}_{2}$ radicals.

The fastest reactions are found for formation of 5 and 6-membered rings. For addition on the inner carbon, larger rings have an entropic disadvantage and the rate coefficient gradually decreases as the cyclic chain becomes longer. For addition on the outer carbon, which is more affected by the geometric impact of the double bond in the TS ring structure, this reduction of the rate for longer chains is not as pronounced, and for rings up to 8 atoms the energetic advantage of the longer chain compensates for the increasing entropic disadvantage. The rate coefficient is most affected by substitution on the double bond, with higher substitution leading to faster ring closure reactions. The stereo-specificity of the substitution on the double bond is most important for ring closure on the outer carbon, where it affects the rate coefficients at $298 \mathrm{~K}$ by an order of magnitude. Preliminary calculations and literature data on oxygenated substituents suggest that the latter can greatly enhance the rate of ring closure.

$\mathrm{H}$-Migration in the product cycloperoxide $\mathrm{RO}_{2}$ radicals was examined for $\mathrm{H}$-atoms implanted directly on the ring structure, including migration of $\alpha$-OOR $\mathrm{H}$-atoms which leads to ring decomposition. The reaction rates were found to be highly dependent on the ring size and migration span, and are poorly correlated to the $\mathrm{H}$-migration rate in non-cyclic $\mathrm{RO}_{2}$ especially below $350 \mathrm{~K}$. On average, the rate of migration is slower than the equivalent migration in non-cyclic $\mathrm{RO}_{2}$. It is proposed that H-migration in substituted cyclic $\mathrm{RO}_{2}$ could be driven mainly by migration of substituent $\mathrm{H}$-atoms.

$\mathrm{H}$-Migration in the cycloperoxide alkoxy radicals formed from the product cycloperoxide $\mathrm{RO}_{2}$ was also examined, and 
compared to SAR-predictions for decomposition reactions. The migration of $\mathrm{H}$-atoms on the ring is typically slower than for non-cyclic alkoxy radicals, owing to the ring strain in the $\mathrm{H}$-migration TS. For the specific molecular skeleton resulting from the ring closure in the parent unsaturated $\mathrm{RO}_{2}$ radical, we find that the dominant fate of the cycloperoxide alkoxy radicals is formation of a carbonyl fragment and a non-cyclic carbonylalkoxy radical. It is proposed that $\mathrm{H}$-migration in cyclic $\mathrm{RO}$ could become important when migrating substituent $\mathrm{H}$-atoms instead of ring $\mathrm{H}$-atoms.

As multi-unsaturated compounds such as isoprene and the monoterpenes make up the bulk of the non-methane organic matter emitted to the atmosphere, unsaturated $\mathrm{RO}_{2}$ radicals are common in the atmosphere, and ring closure reactions could have a significant impact on the oxidation of some volatile organic compounds. For some compounds it was already shown that $\mathrm{RO}_{2}$ ring closure reactions have a large impact on the product distribution. ${ }^{20-23,28}$ However, the overall impact of these reactions on the atmospheric oxidation of such compounds can not be quantified in this work, as it is likely to differ greatly between the individual compounds and thus requires detailed analysis of each specific oxidation mechanism. Specifically, the impact of substituents is not covered in the current work, and could have profound impact on the chemical mechanisms of the individual compounds.

\section{Conflicts of interest}

There are no conflicts to declare.

\section{Acknowledgements}

HMTN and GHTV thank the Ministry of Science and Technology of Vietnam, for sponsoring this work under project number ĐTĐL.CN-68/19.

\section{References}

1 Z. Wang, O. Herbinet, N. Hansen and F. Battin-Leclerc, Exploring hydroperoxides in combustion: History, recent advances and perspectives, Prog. Energy Combust. Sci., 2019, 73, 132-181.

2 F. Battin-Leclerc, Detailed chemical kinetic models for the low-temperature combustion of hydrocarbons with application to gasoline and diesel fuel surrogates, Prog. Energy Combust. Sci., 2008, 34, 440-498.

3 J. Zádor, C. A. Taatjes and R. X. Fernandes, Kinetics of elementary reactions in low-temperature autoignition chemistry, Prog. Energy Combust. Sci., 2011, 37, 371-421.

4 J. Peeters, T. L. Nguyen and L. Vereecken, HOx radical regeneration in the oxidation of isoprene, Phys. Chem. Chem. Phys., 2009, 11, 5935-5939.

5 J. D. Crounse, L. B. Nielsen, S. Jørgensen, H. G. Kjaergaard and P. O. Wennberg, Autoxidation of organic compounds in the atmosphere, J. Phys. Chem. Lett., 2013, 4, 3513-3520.
6 M. Ehn, T. Berndt, J. Wildt and T. Mentel, Highly oxygenated molecules from atmospheric autoxidation of hydrocarbons: A prominent challenge for chemical kinetics studies, Int. J. Chem. Kinet., 2017, 49, 821-831.

7 T. Jokinen, M. Sipila, S. Richters, V.-M. Kerminen, P. Paasonen, F. Stratmann, D. Worsnop, M. Kulmala, M. Ehn, H. Herrmann and T. Berndt, Rapid autoxidation forms highly oxidized $\mathrm{RO}_{2}$ radicals in the atmosphere, Angew. Chem., Int. Ed., 2014, 53, 14596-14600.

8 T. F. Mentel, M. Springer, M. Ehn, E. Kleist, I. Pullinen, T. Kurtén, M. Rissanen, A. Wahner and J. Wildt, Formation of highly oxidized multifunctional compounds: Autoxidation of peroxy radicals formed in the ozonolysis of alkenes deduced from structure-product relationships, Atmos. Chem. Phys., 2015, 15, 6745-6765.

9 F. Bianchi, T. Kurtén, M. Riva, C. Mohr, M. P. Rissanen, P. Roldin, T. Berndt, J. D. Crounse, P. O. Wennberg, T. F. Mentel, J. Wildt, H. Junninen, T. Jokinen, M. Kulmala, D. R. Worsnop, J. A. Thornton, N. Donahue, H. G. Kjaergaard and M. Ehn, Highly oxygenated organic molecules (HOM) from gas-phase autoxidation involving peroxy radicals: A key contributor to atmospheric aerosol, Chem. Rev., 2019, 119, 3472-3509.

10 B. Nozière and L. Vereecken, Direct observation of aliphatic peroxy radical autoxidation and water effects: An experimental and theoretical study, Angew. Chem., Int. Ed., 2019, 58, 13976-13982.

11 L. Vereecken and B. Nozière, H migration in peroxy radicals under atmospheric conditions, Atmos. Chem. Phys., 2020, 20, 7429-7458.

12 A. Miyoshi, Systematic computational study on the unimolecular reactions of alkylperoxy $\left(\mathrm{RO}_{2}\right)$, hydroperoxyalkyl $(\mathrm{QOOH})$, and hydroperoxyalkylperoxy $\left(\mathrm{O}_{2} \mathrm{QOOH}\right)$ radicals, J. Phys. Chem. A, 2011, 115, 3301-3325.

13 F. Zhang and T. S. Dibble, Effects of olefin group and its position on the kinetics for intramolecular $\mathrm{H}$-shift and $\mathrm{HO}_{2}$ elimination of alkenyl peroxy radicals, J. Phys. Chem. A, 2011, 115, 655-663.

14 R. V. Otkjær, H. H. Jakobsen, C. M. Tram and H. G. Kjaergaard, Calculated hydrogen shift rate constants in substituted alkyl peroxy radicals, J. Phys. Chem. A, 2018, 112, 8665-8673.

15 A. B. Guenther, X. Jiang, C. L. Heald, T. Sakulyanontvittaya, T. Duhl, L. K. Emmons and X. Wang, The model of emissions of gases and aerosols from nature version 2.1 (MEGAN2.1): An extended and updated framework for modeling biogenic emissions, Geosci. Model Dev., 2012, 5, 1471-1492.

16 R. Wu, L. Vereecken, E. Tsiligiannis, S. Kang, S. R. Albrecht, L. Hantschke, D. Zhao, A. Novelli, H. Fuchs, R. Tillmann, T. Hohaus, P. T. M. Carlsson, J. Shenolikar, F. Bernard, J. N. Crowley, J. L. Fry, B. Brownwood, J. A. Thornton, S. S. Brown, A. Kiendler-Scharr, A. Wahner, M. Hallquist and T. F. Mentel, Molecular composition and volatility of multigeneration products formed from isoprene oxidation by nitrate radical, Gases/Laboratory Studies/Troposphere/Chemistry (chemical composition and reactions), 2020. 
17 D. Zhao, I. Pullinen, H. Fuchs, S. Schrade, R. Wu, I.-H. Acir, R. Tillmann, F. Rohrer, J. Wildt, Y. Guo, A. Kiendler-Scharr, A. Wahner, S. Kang, L. Vereecken and T. F. Mentel, Highly oxygenated organic molecules (HOM) formation in the isoprene oxidation by $\mathrm{NO}_{3}$ radical, Gases/Laboratory Studies/Troposphere/Chemistry (chemical composition and reactions), 2020.

18 M. Ehn, E. Kleist, H. Junninen, T. Petaja, G. Lonn, S. Schobesberger, M. Dal Maso, A. Trimborn, M. Kulmala, D. R. Worsnop, A. Wahner, J. Wildt and T. F. Mentel, Gas phase formation of extremely oxidized pinene reaction products in chamber and ambient air, Atmos. Chem. Phys., 2012, 12, 5113-5127.

19 I. Pullinen, S. Schmitt, S. Kang, M. Sarrafzadeh, P. Schlag, S. Andres, E. Kleist, T. F. Mentel, F. Rohrer, M. Springer, R. Tillmann, J. Wildt, C. Wu, D. Zhao, A. Wahner and A. Kiendler-Scharr, Impact of $\mathrm{NO}_{\mathrm{x}}$ on secondary organic aerosol (SOA) formation from $\alpha$-pinene and $\beta$-pinene photooxidation: the role of highly oxygenated organic nitrates, Atmos. Chem. Phys., 2020, 20, 10125-10147.

20 L. Vereecken and J. Peeters, Nontraditional (per)oxy ringclosure paths in the atmospheric oxidation of isoprene and monoterpenes, J. Phys. Chem. A, 2004, 108, 5197-5204.

21 L. Vereecken and J. Peeters, A theoretical study of the $\mathrm{OH}$ initiated gas-phase oxidation mechanism of $\beta$-pinene $\left(\mathrm{C}_{10} \mathrm{H}_{16}\right)$ : first generation products, Phys. Chem. Chem. Phys., 2012, 14, 3802-3815.

22 L. Xu, K. H. Møller, J. D. Crounse, R. Otkær, H. G. Kjaergaard and P. O. Wennberg, Unimolecular reactions of peroxy radicals formed in the oxidation of $\alpha$-pinene and $\beta$-pinene by hydroxyl radicals, J. Phys. Chem. A, 2019, 123, 1661-1674.

23 K. H. Møller, R. Otkjær, J. Chen and H. G. Kjaergaard, Double bonds are key to fast unimolecular reactivity in first-generation monoterpene hydroxy peroxy radicals, J. Phys. Chem. A, 2020, 124, 2885-2896.

24 A. Novelli, L. Vereecken, B. Bohn, H.-P. Dorn, G. I. Gkatzelis, A. Hofzumahaus, F. Holland, D. Reimer, F. Rohrer, S. Rosanka, D. Taraborrelli, R. Tillmann, R. Wegener, Z. Yu, A. KiendlerScharr, A. Wahner and H. Fuchs, Importance of isomerization reactions for the $\mathrm{OH}$ radical regeneration from the photooxidation of isoprene investigated in the atmospheric simulation chamber SAPHIR, Atmos. Chem. Phys., 2020, 20, 3333-3355.

25 L. Vereecken, P. Carlsson, A. Novelli, F. Bernard, S. S. Brown, C. Cho, J. N. Crowley, H. Fuchs, W. Mellouki, D. Reimer, J. Shenolikar, R. Tillmann, L. Zhou, A. KiendlerScharr and A. Wahner, Theoretical and experimental study of peroxy and alkoxy radicals in the $\mathrm{NO}_{3}$-initiated oxidation of isoprene, Phys. Chem. Chem. Phys., 2021, 23, 5496-5515.

26 F. Ma, X. Guo, D. Xia, H.-B. Xie, Y. Wang, J. Elm, J. Chen and J. Niu, Atmospheric chemistry of allylic radicals from isoprene: A successive cyclization-driven autoxidation mechanism, Environ. Sci. Technol., 2021, 55(8), 4399-4409.

27 J. Chen, K. H. Møller, P. O. Wennberg and H. G. Kjaergaard, Unimolecular reactions following indoor and outdoor limonene ozonolysis, J. Phys. Chem. A, 2021, 125, 669-680.
28 M. Kaminski, H. Fuchs, I.-H. Acir, B. Bohn, T. Brauers, H.-P. Dorn, R. Häseler, A. Hofzumahaus, X. Li, A. Lutz, S. Nehr, F. Rohrer, R. Tillmann, L. Vereecken, R. Wegener and $\mathrm{A}$. Wahner, Investigation of the $\beta$-pinene photooxidation by $\mathrm{OH}$ in the atmosphere simulation chamber SAPHIR, Atmos. Chem. Phys., 2017, 17, 6631-6650.

29 B. Aumont, S. Szopa and S. Madronich, Modelling the evolution of organic carbon during its gas-phase tropospheric oxidation: Development of an explicit model based on a self generating approach, Atmos. Chem. Phys., 2005, 5, 2497-2517.

30 B. Aumont, M. Camredon, C. Mouchel-Vallon, S. La, F. Ouzebidour, R. Valorso, J. Lee-Taylor and S. Madronich, Modeling the influence of alkane molecular structure on secondary organic aerosol formation, Faraday Discuss., 2013, 165, 105-122.

31 W. P. L. Carter, Gateway to the SAPRC-16 Mechanism Generation System, 2021, http://mechgen.cert.ucr.edu/, last accessed March 2021.

32 Y. Zhao and D. G. Truhlar, The M06 suite of density functionals for main group thermochemistry, thermochemical kinetics, noncovalent interactions, excited states, and transition elements: Two new functionals and systematic testing of four M06-class functionals and 12 other functionals, Theor. Chem. Acc., 2008, 120, 215-241.

33 T. H. Dunning, Gaussian basis sets for use in correlated molecular calculations. I. The atoms boron through neon and hydrogen, J. Chem. Phys., 1989, 90, 1007-1023.

34 S. Grimme, S. Ehrlich and L. Goerigk, Effect of the damping function in dispersion corrected density functional theory, J. Comput. Chem., 2011, 32, 1456-1465.

35 J. L. Bao, J. Zheng, I. M. Alecu, B. J. Lynch, Y. Zhao and D. G. Truhlar, Database of Frequency Scale Factors for Electronic Model Chemistries (Version 4), http://comp. chem.umn.edu/freqscale/index.html.

36 I. M. Alecu, J. Zheng, Y. Zhao and D. G. Truhlar, Computational thermochemistry: Scale factor databases and scale factors for vibrational frequencies obtained from electronic model chemistries, J. Chem. Theory Comput., 2010, 6, 2872-2887.

37 G. D. Purvis and R. J. Bartlett, A full coupled-cluster singles and doubles model: The inclusion of disconnected triples, J. Chem. Phys., 1982, 76, 1910.

38 T. J. Lee and P. R. Taylor, A diagnostic for determining the quality of single-reference electron correlation methods, Int. J. Quantum Chem., 1989, 36, 199-207.

39 J. C. Rienstra-Kiracofe, W. D. Allen and H. F. Schaefer, The $\mathrm{C}_{2} \mathrm{H}_{5}+\mathrm{O}_{2}$ reaction mechanism: High-level ab initio characterizations, J. Phys. Chem. A, 2000, 104, 9823-9840.

40 L. Vereecken and J. Peeters, The 1,5-H-shift in 1-butoxy: A case study in the rigorous implementation of transition state theory for a multirotamer system, J. Chem. Phys., 2003, 119, 5159-5170.

41 C. Eckart, The penetration of a potential barrier by electrons, Phys. Rev., 1930, 35, 1303-1309.

42 H. S. Johnston and J. Heicklen, Tunneling corrections for unsymmetrical Eckart potential energy barriers, J. Phys. Chem., 1962, 66, 532-533. 
43 H. C. Knap and S. Jørgensen, Rapid hydrogen shift reactions in acyl peroxy radicals, J. Phys. Chem. A, 2017, 121, 1470-1479.

44 K. H. Møller, K. H. Bates and H. G. Kjaergaard, The importance of peroxy radical hydrogen-shift reactions in atmospheric isoprene oxidation, J. Phys. Chem. A, 2019, 123, 920-932.

45 L. Vereecken and J. Peeters, A structure-activity relationship for the rate coefficient of H-migration in substituted alkoxy radicals, Phys. Chem. Chem. Phys., 2010, 12, 12608-12620.

46 L. Vereecken, A. Novelli and D. Taraborrelli, Unimolecular decay strongly limits concentration of Criegee intermediates in the atmosphere, Phys. Chem. Chem. Phys., 2017, 19, 31599-31612.

47 IUPAC Subcommittee on Atmospheric Chemical Kinetic Data Evaluation, 2017.

48 K. H. Møller, T. Kurtén, K. H. Bates, J. A. Thornton and H. G. Kjaergaard, Thermalized epoxide formation in the atmosphere, J. Phys. Chem. A, 2019, 123, 10620-10630.

49 L. Vereecken, T. L. Nguyen, I. Hermans and J. Peeters, Computational study of the stability of $\alpha$-hydroperoxyl- or $\alpha$-alkylperoxyl substituted alkyl radicals, Chem. Phys. Lett., 2004, 393, 432-436.

50 O. M. Anglada, R. Crehuet and J. S. Francisco, The stability of $\alpha$-hydroperoxyalkyl radicals, Chem. - Eur. J., 2016, 22, 18092-18100.

51 M. E. Jenkin, R. Valorso, B. Aumont and A. R. Rickard, Estimation of rate coefficients and branching ratios for reactions of organic peroxy radicals for use in automated mechanism construction, Atmos. Chem. Phys., 2019, 19, 7691-7717.
52 C. Fittschen, The reaction of peroxy radicals with $\mathrm{OH}$ radicals, Chem. Phys. Lett., 2019, 725, 102-108.

53 E. Assaf, C. Schoemaecker, L. Vereecken and C. Fittschen, Experimental and theoretical investigation of the reaction of $\mathrm{RO}_{2}$ radicals with $\mathrm{OH}$ radicals: Dependence of the $\mathrm{HO}_{2}$ yield on the size of the alkyl group, Int. J. Chem. Kinet., 2018, 50, 670-680.

54 J. J. Orlando, G. S. Tyndall and T. J. Wallington, The atmospheric chemistry of alkoxy radicals, Chem. Rev., 2003, 103, 4657-4690.

55 R. Atkinson, Rate constants for the atmospheric reactions of alkoxy radicals: An updated estimation method, Atmos. Environ., 2007, 41, 8468-8485.

56 X. Xu, E. Papajak, J. Zheng and D. G. Truhlar, Multistructural variational transition state theory: Kinetics of the 1,5-hydrogen shift isomerization of the 1-butoxyl radical including all structures and torsional anharmonicity, Phys. Chem. Chem. Phys., 2012, 14, 4204-4216.

57 P. Cassanelli, R. A. Cox, J. J. Orlando and G. S. Tyndall, An FT-IR study of the isomerization of 1-butoxy radicals under atmospheric conditions, J. Photochem. Photobiol., A, 2006, 177, 109-115.

58 L. Vereecken and J. Peeters, Decomposition of substituted alkoxy radicals-part I: A generalized structure-activity relationship for reaction barrier heights, Phys. Chem. Chem. Phys., 2009, 11, 9062-9074.

59 A. Novelli, C. Cho, H. Fuchs, A. Hofzumahaus, F. Rohrer, R. Tillmann, A. Kiendler-Scharr, A. Wahner and L. Vereecken, Experimental and theoretical study on the impact of a nitrate group on the chemistry of alkoxy radicals, Phys. Chem. Chem. Phys., 2021, 23, 5474-5495. 